\title{
New avenues for HRM roles: A systematic literature review on HRM in hybrid organizations
}

German Journal of Human Resource Management

(C) The Author(s) 2021

Article reuse guidelines: sagepub.com/journals-permissions DOI: $10.1177 / 23970022211049533$ journals.sagepub.com/home/gjh

\section{Anja Belte}

Faculty of Economics and Management, Leibniz University Hannover, Germany

\begin{abstract}
In recent decades, the emergence of hybrid organizational forms has placed new demands on the role of human resource management (HRM) contributing to organizational goals. Moreover, research emphasizes that the increasing hybridity of contexts, stakeholder requirements, and goals lead to organizational tensions that, if not properly addressed, can lead to organizational downfall. However, although organization and management research recognize the importance of elaborating HRM roles for hybrid contexts, drawing upon findings from the hybrid literature has been widely neglected. Thus, by mapping the research landscape regarding hybridity, this article provides insight into the configuration of organizational HRM roles and functions that contribute to the development of hybrid goals and are associated to the management of tensions. Significantly, this article introduces three specific HRM roles-hybrid strategist, capability adapter, and identification generator-as essential HRM roles for hybrid contexts.
\end{abstract}

\section{Keywords}

HRM role, Human resource management, hybrid organizations, systematic review, tensions

\section{Introduction}

Strategic Human Resource Management (SHRM) has become established "as the pattern of planned human resource deployments and activities intended to enable an organization to achieve its goals" (Wright and McMahan, 1992: 298). As such, human resource (HR) competencies have been highlighted and human resource management (HRM) roles have been developed that affect personal effectiveness and business results (Ulrich et al., 2012). However, in recent decades, changes have occurred in the environment such as requirements from stakeholders for more sustainability and superseding HRM roles as

\section{Corresponding author:}

Anja Belte, Faculty of Economics and Management, Leibniz University Hannover, Königsworther Platz I, Hannover 30167, Germany.

Email: belte@pua.uni-hannover.de 
only adding value when contributing to performance goals (Ehnert, 2014; Wright et al., 2018). Although, the organization and management literature has recognized the sustainability development and organizational changes with regard to the development of HRM and its role (e.g. Aust et al., 2020; Gerpott, 2015; Ulrich and Dulebohn, 2015), the majority of HRM roles still focus on a profit orientation. As such, existing HRM roles are too focused on SHRM to meet sustainability requirements and contribute to sustainability goals. Moreover, the opening of SHRM research in terms of sustainability has further intensified the debate on (paradoxical) tensions within HRM (Aust et al., 2020; Ehnert, 2014; Keegan et al., 2019), setting additional requirements in configuring contemporary HRM roles.

Sparked by the call for greater sustainability, the organizational landscape has changed, fostering the emergence of new hybrid forms. Hybrid organizations embrace several institutional logics (Dufays and Huybrechts, 2016; Van den Broek et al., 2014), span institutional boundaries (Battilana and Dorado, 2010), and design their business models based on the remedies of particular social or environmental issues (Haigh et al., 2015). Consequently, hybrid organizations offer compelling information on an area confronted with multiple demands and goals, where the emergence of (paradoxical) tensions is the daily norm and their management is a core responsibility (Battilana and Dorado, 2010). Hence, examining hybridity may help understand the configuration of HRM roles from a hybrid perspective, enhancing paradoxical theoretical approaches to handle tensions (Aust et al., 2020; Keegan et al., 2019; Ulrich and Dulebohn, 2015). Although hybrid organizations provide an ideal space to specify HRM roles, these have been neglected so far by HRM scholars (Doherty et al., 2014; Newman et al., 2015). This poses problems for HR practitioners, as they must remain capable of contributing to strategic goals in an increasing hybrid environment. Hence, approaching HRM from a hybrid perspective is essential both for the theoretical development of HRM roles and for the guidance of HR practitioners. Thus, to address this gap and provide an avenue for HRM roles in hybrid contexts, the following research question is posed: How are HRM roles configured in hybrid organizations?

As research on HRM in hybrid organizations remains scarce and fragmented, this study addresses this question by providing a comprehensive systematic review of recent studies of HRM in hybrid organizations published between 1999 and 2020. This article applies a five-step approach to systematic reviews and employs a structured content analysis for 40 peer-reviewed articles (Denyer and Tranfield, 2009). To elaborate the configuration of HRM roles in hybrid organizations current frameworks of sustainable HRM, along with frameworks that address paradox perspective approaches, were compared to identify categories of HRM concepts (e.g. Aust et al., 2017; Beer et al., 2015; Farndale and Paauwe, 2018). First, these categories (determinants, content, and outcomes) were established as a classification system in the subsequent analysis of the findings of the literature selection. Second, HRM functions are delineated from the review findings that focus on these categories leading to the configuration of three contemporary HRM roles for hybrid organizations: hybrid strategist, capability adapter, identification generator. 
Therefore, this article contributes in theoretical and practical terms. Based on a detailed literature analysis, HRM roles that provide an organizational value are proposed by ensuring that the services that HRM offers inside the organization are aligned with outside expectations (e.g. Beer et al., 1985, 2015). These roles expand the scope of HRM and its contribution to the organizational field. Furthermore, this article introduces HRM roles that can adapt paradoxical thinking using approaches from the paradox theory to handle tensions (Aust et al., 2017). In practical terms, it provides detailed information about the HRM functions required for future HRM roles to contribute to organizational sustainability and managing tensions.

\section{Conceptual foundations for HRM roles in hybrid organizations}

To elaborate the configuration of HRM roles in hybrid organizations, theoretical and conceptual approaches of the two domains are first illustrated. The hybrid literature refers to hybrid organizations as those that combine multiple institutional forms (Jay, 2013; Lee and Battilana, 2013; Tracey et al., 2011), distinct institutional logics (Battilana and Dorado, 2010), and identities (Albert and Whetten, 1985; Glynn, 2000; Hsieh et al., 2018). Hybrid organizations can occur in different forms (Litrico and Besharov, 2019). Accordingly, this review will also highlight the diversity of hybrid organizations, such as social enterprises, and the requirements that are imposed on the configuration of HRM roles (Battilana and Lee, 2014; Jay, 2013). To explain the influence of institutional changes on organizational forms, logics, and practices, institutional theory (Meyer and Rowan, 1977) and neo-institutional theory (Powell and DiMaggio, 1991) have paved the way for the concept of institutional logics. Institutional logics are described as the rules of the game that - once integrated into an organizational context - shape its practices and the social identities of its members (Friedland and Alford, 1991). Moreover, according to Skelcher and Smith (2015), hybridization is viewed as a process in which plural logics and actor identities are involved within an organization, leading to several possible organizational outcomes. Furthermore, research on institutional logics has shown that different logics may coexist over time (Reay and Hinings, 2009) or lead to tensions (Greenwood et al., 2011; Van den Broek et al., 2014).

This plurality makes hybrid organizations an ideal field to elaborate on HRM roles and their functions in hybrid contexts, meeting multiple demands such as sustainability. This integration approach of institutional logics into the organizational context can also be identified in a broader sense in existing HRM approaches. Previous research developed the concept of sustainable HRM to address the narrow SHRM orientation in grappling with the relationship between HRM practices and outcomes beyond financial outcomes (Ehnert, 2009; Kramar, 2014; Podgorodnichenko et al., 2020). Consequently, HRM scholars have increasingly drawn attention to the role of HRM in developing sustainable HRM systems that consider significant societal challenges and long-term influences, such as climate change and workforce demographics, by applying an outside-in perspective (Aust et al., 2020; Dyllick and Muff, 2016). Ulrich and Dulebohn (2015: 
191) emphasize that applying an outside-in perspective "represents a seismic shift in how HR thinks and acts." Moreover, they indicate that applying an outside-in perspective leads to future HRM roles that create value by ensuring that services that HRM offers inside the organization are aligned to outside expectations (see also Beer et al., 1985, 2015). In addition, Farndale and Paauwe (2018) point out that context needs to be integrated into theoretical developments. They emphasize that a broader context-centric analysis specifies the relationship between HRM and a wider performance orientation.

As the introduction of sustainability in a strategic context is initially seen as contradictory (comparability of short- and long-term goals), thus leading to (further) tensions within HRM, the theoretical approach of paradoxes has become particularly prominent (Putnam et al., 2016). For instance, Ehnert (2009, 2014) developed a paradox framework for sustainable HRM, which illustrates the key tensions between the efficient utilization of people and maintaining human capabilities. Moreover, Keegan et al. (2019) illustrate how the paradox perspective can provide insights for addressing tensions by including different responses in using a set of fictional hiring practices. To manage tensions, these approaches imply the configuration of HRM roles that adapt paradoxical thinking to handle tensions simultaneously (Putnam et al., 2016). To examine tensions, the hybrid literature establishes new standards. There is extensive evidence on the emergence and management of hybrid organizations, which highlights tensions as a key challenge for them. Tensions can occur in a variety of ways. In the hybrid literature, a distinction is commonly drawn between external and internal tensions and between organizational, group, and individual levels of tension (Battilana et al., 2015). For example, supported by approaches of institutional and stakeholder theory, the main challenge of external tensions, such as competing stakeholder demands, are legitimation problems with regard to divergent institutional logics (Pache and Santos, 2010). Internal tensions at the organizational level arise in particular when leaders struggle to articulate a clear strategy (e.g. Tracey et al., 2011). Supported by identity theory approaches, internal tensions can lead to mission drift that impairs the ability of an organization to act effectively and jeopardizes its existence (Albert and Whetten, 1985; Ashforth and Reingen, 2014; Glynn et al., 2020). At the group or individual level, tensions arise over contradictory values, identities, mindsets, or skillsets of employees (Besharov and Smith, 2014; Glynn, 2000).

In terms of paradox-theoretical approaches, the hybrid literature offers several insights. Smith and Lewis (2011) propose a framework for categorizing paradoxical tensions - belonging, learning, organizing, and performing - as four paradox categories representing the core activities and elements of organizations in linking former theories. Concerning the tensions inherent in (sustainable) HRM systems, these findings could improve our understanding of the functions of HRM roles in developing systems and practices suited in managing paradoxical conditions and applying an outside-in perspective (Aust et al., 2020; Ulrich and Dulebohn, 2015). Finally, as hybrid organizations aim to achieve multiple goals, HRM roles that are adjusted on the basis of this context can contribute to the development of multiple (sustainability) goals.

Thus, the theoretical and conceptual diversity offered by the research field of hybrid organizations is an ideal place to explore requirements for the configuration of HRM roles. To elaborate the configuration of the HRM roles, the next section undertakes the systematic exploration of this hybrid literature. 


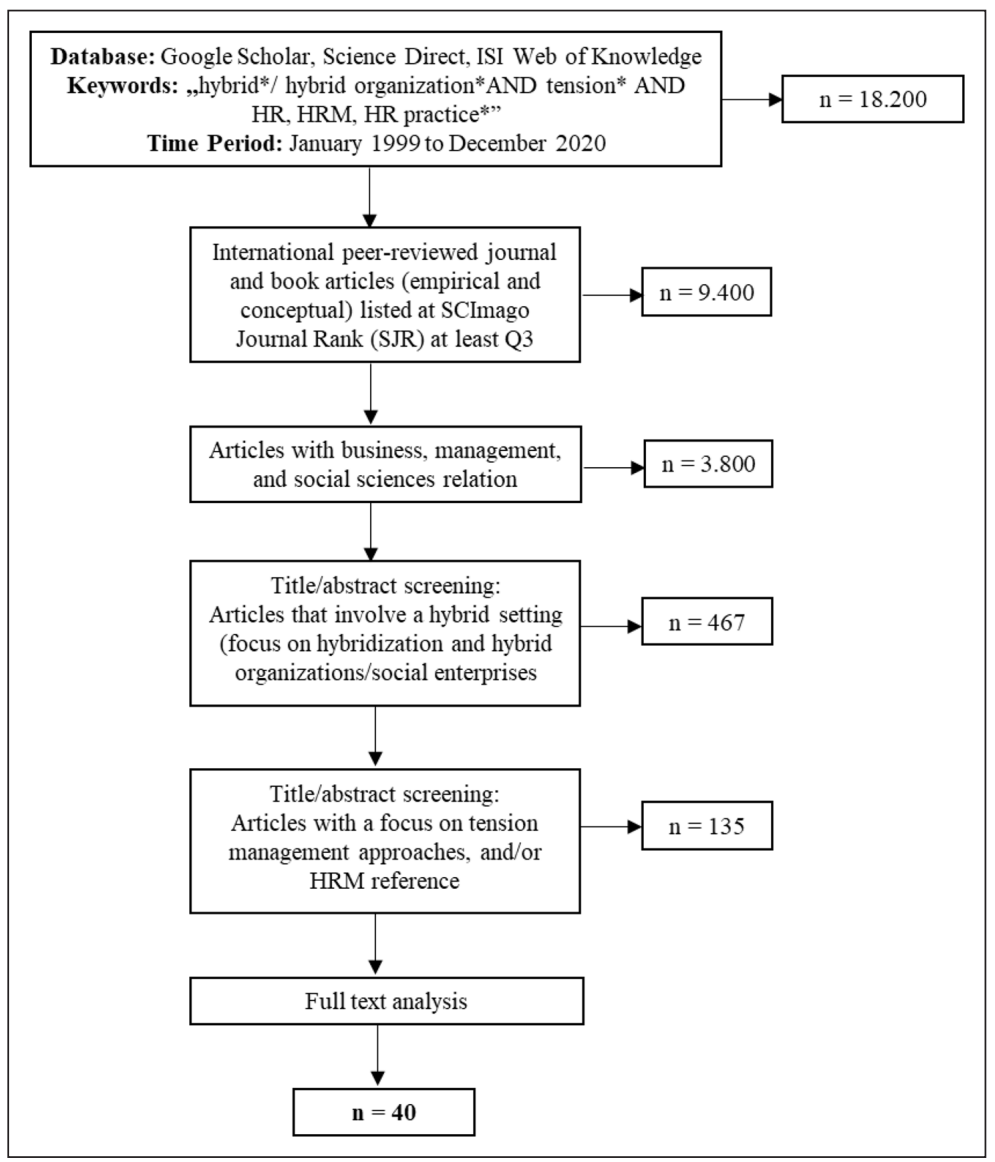

Figure I. Systematic review process.

\section{Method and review agenda}

Different methods for analyzing and synthesizing the extant literature can provide researchers with a comprehensive overview of the empirical findings (Denyer and Tranfield, 2009). The salient method is a systematic literature review conducted in five stages to address the research question (Denyer and Tranfield, 2009; Tranfield et al., 2003) (see Figure 1).

First, using the Web of Science, Science Direct, and Google Scholar, the bibliographic databases and journals were searched to identify appropriate high-quality HRM, general management, and nonprofit and public management journals. The temporal scope of the chosen literature was set on studies published between 1999 and 2020 arising from the demand for bridging intra-organizational and institutional levels of analysis in the late 
1990s, which shifted the focus toward HR policies and practices. Second, in addressing the research question, a keyword search of articles using a combination of relevant hybrid and HRM search terms, such as hybrid*/hybrid organization* AND tension* AND *HR, HRM, HR practice*, was conducted. The keywords applied were derived from the research question. As research on HRM in hybrid organizations remains scarce, the application of the search term "role" was omitted in the selection of the articles. To avoid excluding essential HRM-related articles, focus was laid on the functions of HRM for deducing HRM roles. Third, to ensure that the articles included in the review met high scientific standards and comprised only valid findings with the greatest influence on the field, those journals that were not listed according to SCImago Journal and Country Rank at least on Q3 were excluded. ${ }^{1}$ Fourth, these articles were further refined based on a set of carefully defined inclusion and exclusion criteria. For example, articles that investigate hybridity (forms, identities, and logics) in a technical or medical background were excluded. As hybridity can occur in different forms (Litrico and Besharov, 2019), this diversity was taken into account in the inclusion of the studies. As such, studies that involve a hybrid setting, such as social enterprises, and examine hybridization in terms of combining logics, identities, and forms in a profit, public, or nonprofit context were included. Additionally, due to the small number of articles, the HR reference was expanded to include studies related to HR systems, structures, practices, and influencing factors on HR architecture resulting in a sample of 135 articles that met the inclusion criteria. In the fifth and final stage, these articles were subjected to a full-text analysis, resulting in the further reduction of outliers and a final dataset of 40 articles.

Several observations arose from the detailed examination of these studies. Before 2010, only one article could be identified that contained a reference to hybridity and HRM simultaneously. Between 2014 and 2020, an increased publication rate of four publications on average can be observed. However, what is worth noting is the significant leap from two publications in 2014 to seven publications in 2015 and the drop to only one publication in 2017. Nevertheless, no specific reason could be identified for this development. With regard of the range of journal and book publications, (see Table 1) the highest number is featured in Public Administration, followed by the International Journal of Human Resource Management.

Most articles reported empirical findings $(n=24)$ with a clear focus on qualitative data $(n=16)$, followed by six quantitative studies and two mixed approaches. It is noticeable that the proportion of empirical studies rises with the increasing actuality of the publication. However, several conceptual articles $(n=16)$ could be identified. The content of conceptual studies, especially in earlier publications, addresses response strategies toward tensions (Pratt and Foreman, 2000). Another focus is the development of a business model for hybrid organizations (Santos et al., 2015), the conceptualization of hybrid organizing (Battilana and Lee, 2014; Battilana et al., 2017), the configuration of HRM systems (Martin et al., 2016; Ridder et al., 2012), and leadership (Smith et al., 2012). Theoretical foundations originate mainly from hybrid, HRM, and leadership literature. Significantly, regarding the hybrid literature, most studies applied institutional and stakeholder theory to explain the determinants of HRM systems and practices. Paradoxical and identity theory approaches were applied to examine the dual outcome perspective and leadership skills are required in hybrid contexts. 
Table I. Overview of journal and book publications on HRM in hybrid organizations.

Journals/books and number of publications

Public Administration (4)

International Journal of Human Resource Management (3)

Academy of Management Journal (2)

Academy of Management Review (2)

California Management Review (2)

European Management Journal (2)

Human Resource Management (2)

Human Resource Management Review (2)

Journal of Social Entrepreneurship (2)

Organization Studies (2)

Academy of Management Annals (I)

Academy of Management Learning and

Education (I)

Administrative Science Quarterly (I)

British Journal of Management (I)

Business Ethics Quarterly (I)

Health Services Management Research (I)

Human Resource Management Journal (I)

International Review of Administrative

Science (I)

International Small Business Journal (I)

Journal of Asia Business Studies (I)

Journal of Business Research (I)

Nonprofit and Voluntary Sector Quarterly (I)

Public Management Review (I)

Research in Organizational Behavior (I)

Social Enterprise Journal (I)

Springer International Publishing (I)

The SAGE Handbook of Organizational

Institutionalism (I)
Authors

Fossestøl et al. (20I5), Gulbrandsen et al.

(20I5), Krøtel and Villadsen (20I6), McGivern et al. (2015)

Hsieh et al. (20I8), Melnik et al. (20I3), Zhang et al. (2018)

Battilana and Dorado (20I0), Pache and Santos (20I3)

Pache and Santos (20I0), Pratt and Foreman (2000)

Haigh et al. (20I5), Santos et al. (20I5)

Martin et al. (20I6), Ohana and Meyer (2010)

Conway et al. (20I6), Roumpi et al. (20I9)

Ren and Jackson (2020), Ridder et al. (2012)

Al Taji and Bengo (2019), Bruneel et al. (2016)

Currie and Spyridonidis (20I6), Mair et al.

(20I5)

Battilana and Lee (2014)

Smith et al. (20I2)

Smith and Besharov (2019)

Burgess and Currie (2013)

Smith et al. (20I3)

Giacomelli et al. (2019)

Alvehus (2018)

Desmarais et al. (2019)

Dufays and Huybrechts (2016)

Napathorn (2018)

Moses and Sharma (2020)

Ridder and McCandless (20I0)

Powell et al. (2019)

Ebrahim et al. (2014)

Imperatori and Ruta (2015)

Winkler and Portocarrero (2018)

Battilana et al. (2017)

HRM-specific topics in the hybrid literature include retention and turnover studies. In this context, commitment, job satisfaction, and involvement have been investigated. Moreover, hiring and socialization practices could be identified as essential HR references. Theoretical foundations that were applied in this context were the leader-member exchange (LMX) theory (Graen and Uhl-Bien, 1995), the job demands-resources (JD-R model) (Bakker and Demerouti, 2007), and the signaling theory (Bowen and Ostroff, 
2004). Finally, the focus on capability development in hybrid contexts is seen to be gaining increasing interest.

For the subsequent data analysis, the categories (determinants, content, and outcomes) were derived from a comparison of existing frameworks of sustainable HRM and frameworks that address tensions from a paradox perspective (Aust et al., 2017; Beer et al., 2015; Farndale and Paauwe, 2018). These categories were applied as a classification system to code, analyze, and order the findings of the selected literature base. To identify further topics from the data, a structured content analysis was carried out moving from the initial codes to patterns in the data to key themes. First, the selected articles were coded with these categories. Iterating between these categories and the literature base, further codes could be identified that emerged during the analysis. In this context, several articles are labeled with multiple codes as they contain multiple categories (see Table 2).

In the second stage of analysis, the selected studies were examined in a second content analysis based on the code list. Patterns could be identified (Gioia et al., 2013) by applying the codes and grouping topic-specific content. Finally, key themes could be aggregated by iterating between the articles and the patterns, such as "organizational strategy and paradoxical manager" concerning determinants, "HRM systems" concerning the content, and "organizational and societal outcomes" for outcomes. Figure 2 highlights these key themes and demonstrates the relationships that could be observed between them.

\section{The configuration of HRM roles in hybrid organizations}

By applying the terms in evaluating the results, HRM functions could be delineated to each category that provides a base for the configuration of HRM roles: hybrid strategist, capability adapter, identification generator (see Figure 2).

\section{HRM role configuration: Determinants}

The first part of the figure refers to the determinants (1) of HRM and its corresponding functions that indicate the role of the hybrid strategist (A). The hybrid strategist role is defined as an organizational role that considers paradoxical strategic goals and combines external and internal perspectives. The data analysis reveals four themes: (1a) contextual factors, (1b), tensions, (1c) paradoxical manager, and (1d) organizational strategy. The hybrid literature emphasizes institutional logics and stakeholder demands as contextual factors (1a). Despite the extant SHRM literature frequently assuming a dichotomous distinction between profit and social logics, the review revealed several differentiated institutional logics that might impose different requirements on the role of SHRM in designing HRM systems. These logics stem from multiple stakeholder demands. For example, Desmarais et al. (2019) characterized the logics of individualization, contractualization, formalization, and politicization affecting the internal dynamics among several stakeholders like elected officials, HR professionals, and management. Their study indicated that political logics, influenced by powerful external stakeholders, shapes HRM practices and systems. Similarly, Battilana and Dorado (2010) noted that HRM decisions invoke micro-negotiations in which logics compete because they are mobilized by stakeholders in a differentiated way. 


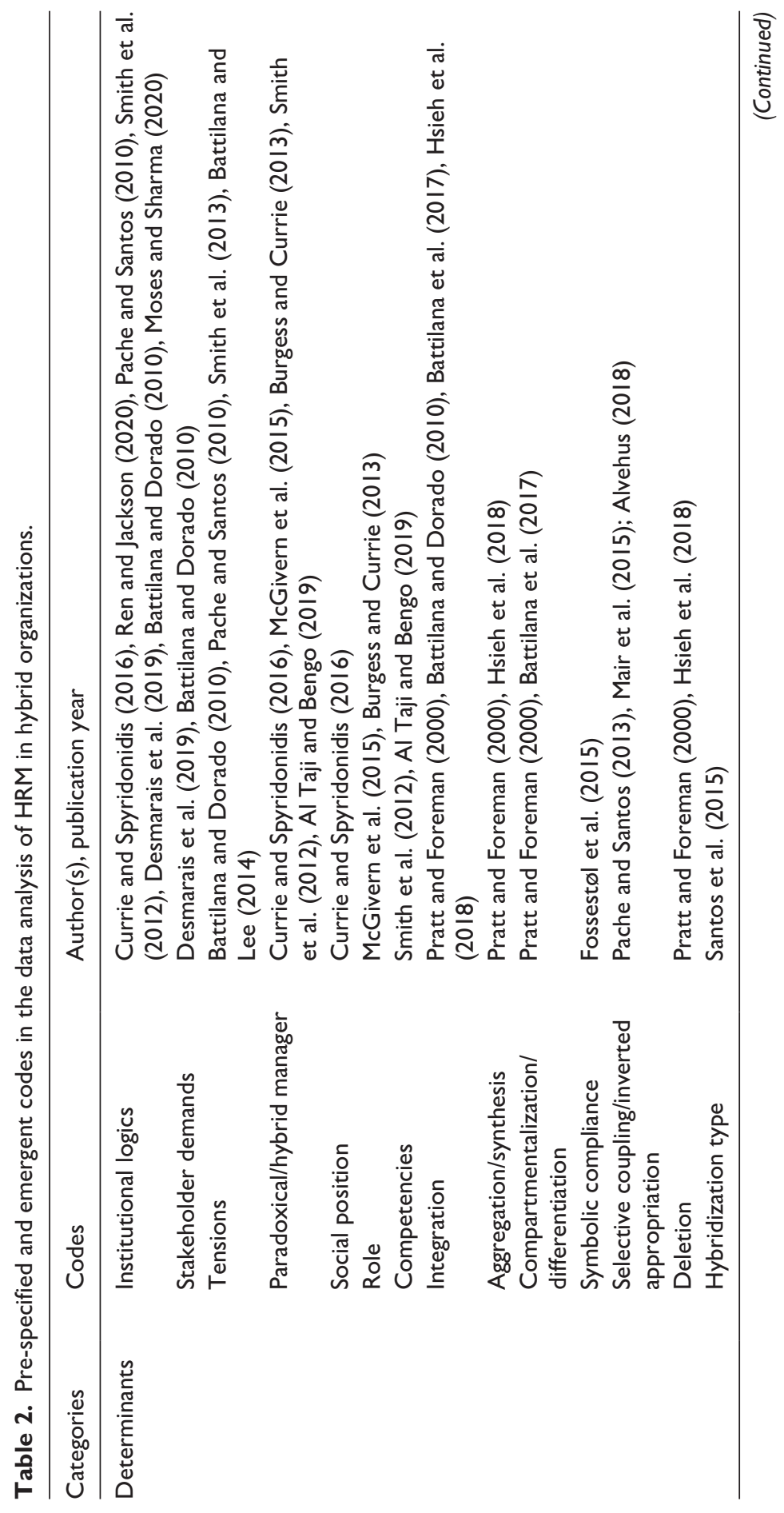




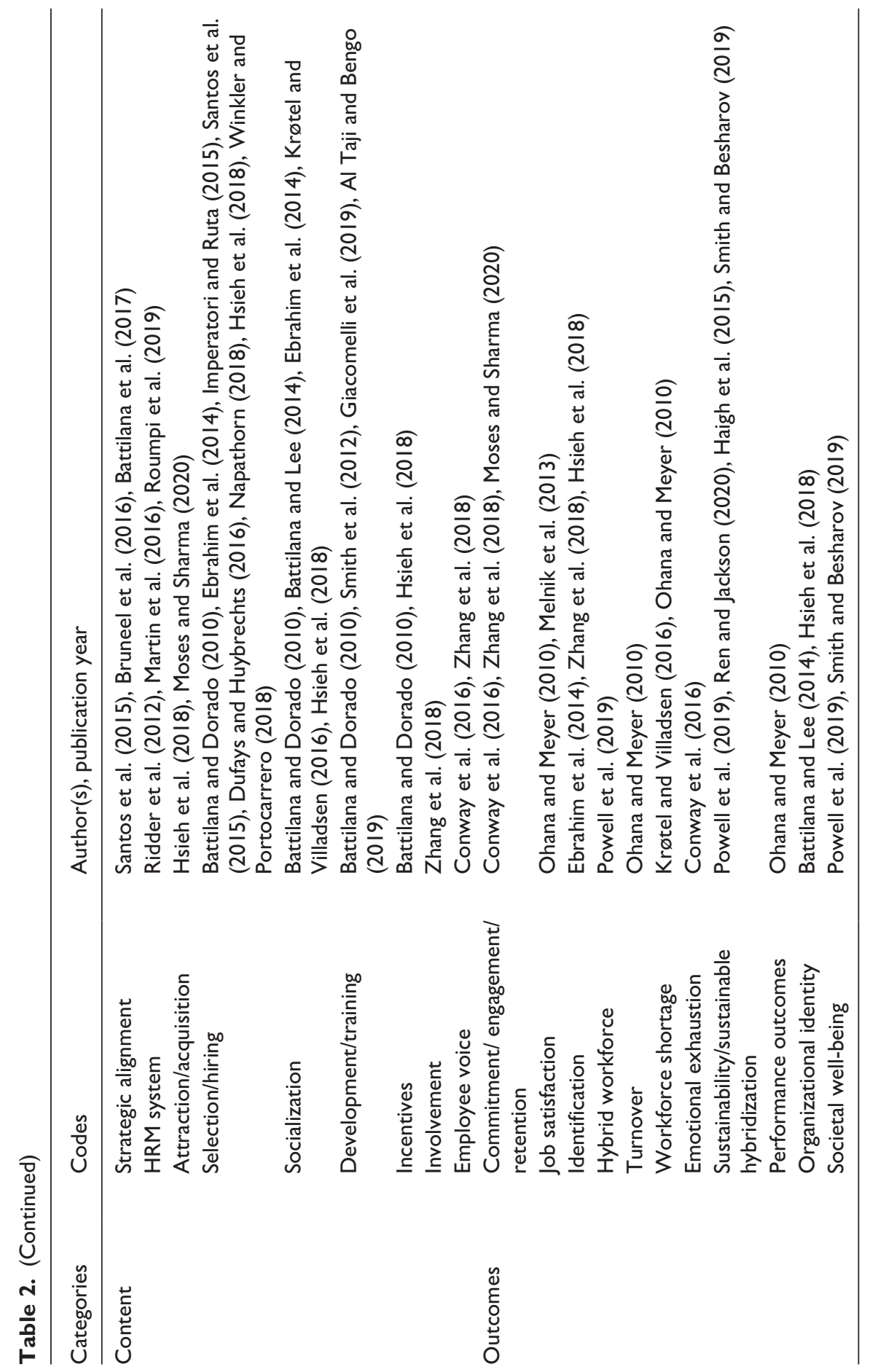




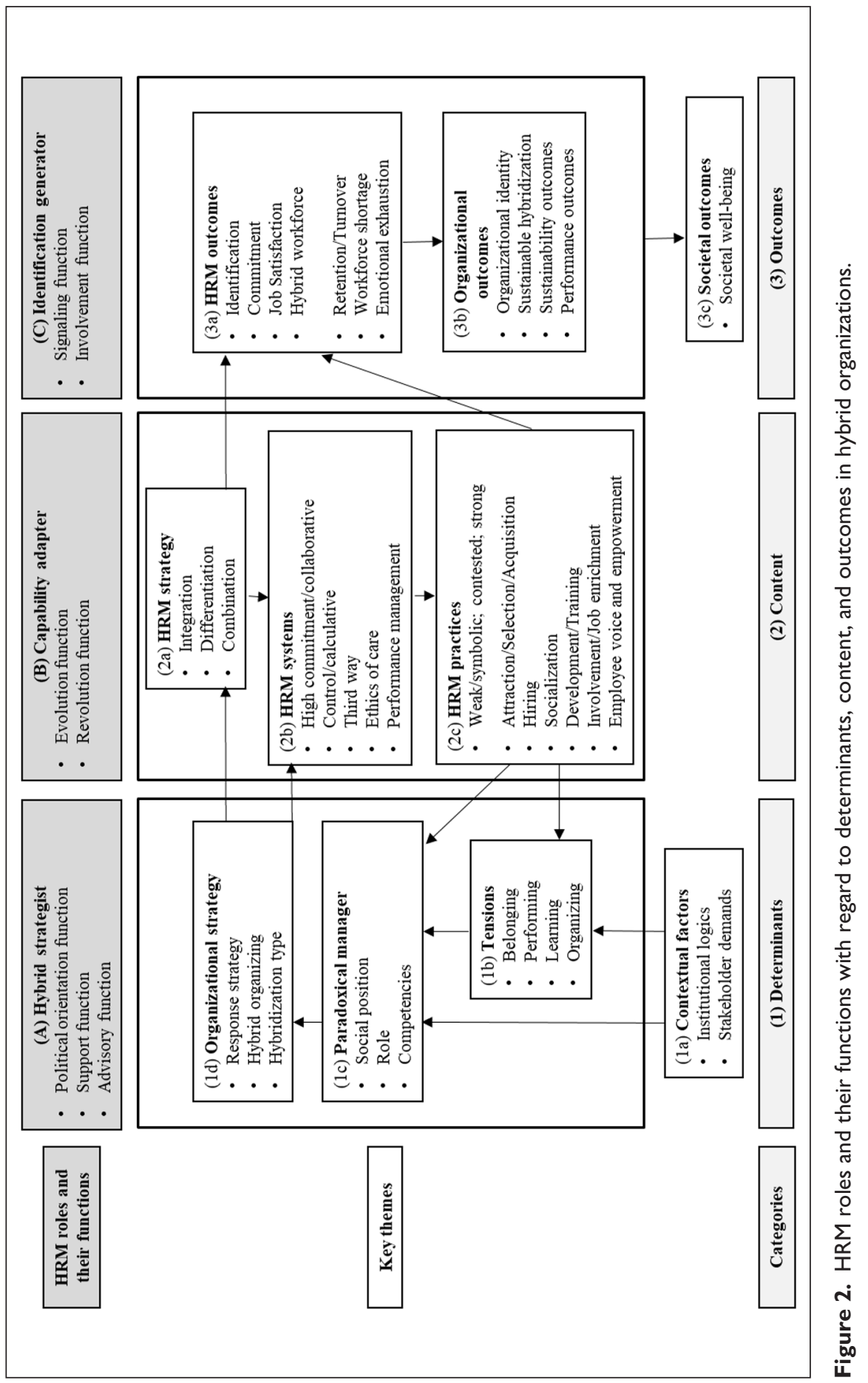


Hence, the political orientation function decisively influences the emergence of the hybrid strategist (A) by addressing politically motivated intentions and requirements. The political orientation function refers to the consideration and non-consideration of key stakeholder demands, which are either integrated into strategic decisions or are ignored.

The review further indicates that contextual factors, such as different institutional logics, generate tensions (1b) when logics that reflect various stakeholder demands are transferred into the organization and are combined or preferred over existing structures and practices. These conflicting demands also have implications for certain response strategies and the design of HRM systems and practices that infuse HR practitioners' roles (Keegan et al., 2019). As indicated in the conceptualization of hybrid organizations, tensions and their management play an essential role in hybrid contexts. The hybrid literature mainly distinguishes between external and internal tensions manifesting at the organizational group or individual levels. Smith et al. (2013) differentiated belonging, performing, learning, and organizing tensions, containing paradoxical elements. For example, belonging tensions emerge from divergent subgroup identities and between subgroups and the organization. Performing tensions emerge from divergent outcomes, like, metrics, and stakeholders. Learning tensions are conflicts of growth, scale, and change that emerge from divergent time horizons, and organizing tensions emerge from divergent internal dynamics, including structures, cultures, practices, and processes (Smith et al., 2013). The intensity and relevance of these tensions have implications for various response strategies that are visible in the organizational strategy (1d).

Moreover, the present research indicates that paradoxical manager(s) (1c) can be understood as mediators between tensions $(1 \mathrm{~b})$ and corresponding organizational strategy (1d), as well as between contextual factors (1a) and organizational strategy (1d). Similarly, the hybrid literature indicates that paradoxical managers, also referred as hybrid managers, are mediating persons looking through the "two-way window" (Llewellyn, 2001: 593). As logics are not fixed, relationships between multiple logics and their influences on organizational strategy (1d) and HRM strategy (2a) might be subject to the interpretation of logics, and inherent logics held by these actors. Especially within public service organizations, hybrid managers are considered important in interpreting dual logics and enacting strategic decisions (Currie and Spyridonidis, 2016; McGivern et al., 2015). Regarding the existence of inherent logics as well as the interpretation of logics, the review results show a connection between the social position and the manager's role regardless of the hierarchical level at which the manager is located. For example, Currie and Spyridonidis (2016) showed that, although performance and financial pressures threatened the survival of an organization, nurses stayed with the former professional logics to sustain their expert role and social position. The study notes that managerial logics are implemented if the social position of hybrid managers is not threatened. McGivern et al. (2015) also emphasize this aspect. Moreover, under the synonym of pluralistic managers, the studies by Besharov (2014) and Perkmann et al. (2019) emphasize the relevance of managers - who need to be aware of different logics - in building hybrid spaces with hybridized practices. These studies show that the influence of hybrid or pluralistic managers can have a decisive impact on organizational strategy and SHRM. However, HRM practices may be important in enhancing hybrid thinking. 
The configuration of a hybrid strategist (A) is also indicated by the support and advisory function of the hybrid manager in their interpretation of different logics and the establishment of strategic responses. Returning to organizational strategy (1d), these functions can be clarified. The hybrid literature emphasizes that tensions require different strategic management approaches integrated into the organizational strategy and influencing the alignment of HRM systems and practices. These management strategies are based on different theoretical approaches that are particularly relevant for understanding the tensions that emerge between social missions and business ventures. For example, the institutional theory focuses on the relationship between organizations and their environments, offering insight into the tensions of organizing within social enterprises (Battilana and Dorado, 2010; Tracey et al., 2011). Organizational identity research offers insights into belonging tensions within social enterprises, and paradox theory extends the understanding of the nature and management of multiple types of tensions within social enterprises (Smith et al., 2013). Applying these theoretical lenses, the hybrid literature reveals a range of response strategies. For example, based on organizational identity theory, Pratt and Foreman (2000) identify four major types of structural responses: compartmentalization, integration, aggregation, and deletion. Compartmentalization occurs when the organization preserves all current identities but fails to attain any synergy among them. Contrarily, in the case of integration, multiple identities are fused into one. Aggregation combines the former approaches by retaining all identities while forging links between them. Finally, deletion occurs when managers eliminate one or more identities due to resource constraints, a lack of stakeholder support, or synergy between the identities. Hsieh et al. (2018) identify similar management approaches, but their synthesis approach emphasizes the connection of identities more than aggregation. Thus, the support and advisory function of HRM is specified by the implementation of certain response strategies and the task of linking organizational strategy with HRM strategy.

Battilana and Lee (2014: 398). They introduce the concept hybrid organizing, which they define as "the activities, structures, processes and meanings by which organizations make sense of and combine aspects of multiple organizational forms." Complementing the various literatures on organizational hybridity they argue that hybrid organizing is at play in five key areas of organizational life such as core organizational activities, workforce composition, organizational design, inter-organizational relationships, and organizational culture. Regarding workforce composition, Battilana and Lee (2014) emphasize that social enterprises, straddling with the social and commercial sector, are unlikely to select employees whose skills align with a hybrid work context. However, different skills that do not fit the hybrid context can create tension. As such, the hybrid organization has to establish a way that allows individuals from different backgrounds to work together.

Interestingly, the results of the review show that when organizational (response) strategies are linked to HRM strategies and practices, the transfer is examined in building a bridge between the determinants and content of SHRM in hybrid organizations. Hsieh et al. (2018) provide information on how organizational strategy (1d) influences HRM strategy (2a) by translating strategic objectives into HRM practices to foster organizational identification management. In contrast to Hsieh et al. (2018), Pache and Santos (2013) indicate that strategic decisions are not transferred to HRM strategies but remain 
in the organizational strategy. The institutional logics perspective shows that social enterprises selectively couple intact elements prescribed by competing logics. The findings indicate that organizations that originate from the commercial sector reacted more to social demands and vice versa. Pache and Santos (2013) labeled this strategy the Trojan horse. It involves strategically incorporating (legitimated) logics from other sectors to gain legitimacy and acceptance. This is supported by Mair et al. (2015), who divide hybrids into a conforming type that relies on the prioritization of a single institutional logic and a dissenting type that uses defiance, selective coupling, and innovation as mechanisms to combine and balance different institutional logics. Both studies indicate that hybridization efforts remain strategic decisions in the organizational strategy (1d), while a "real" transfer into HRM strategy (2a) and further HRM systems (2b) or HRM practices (2c) is absent or is only formulated for appearance and legitimation purposes. Moreover, Alvehus (2018) shows that hybridity between conflicting logics may appear on the management level, visible in organizational strategies, whereas a single logic dominates the HRM strategy. This response strategy, referred to as symbolic compliance, reduces the number of logics to which the organization attends, retaining them only in principle in their organizational strategy (Fossestøl et al., 2015).

\section{HRM role configuration: Content}

The second part of the figure refers to content (2) of HRM and its corresponding functions that indicate the HRM role of the capability adapter (B) (see Figure 2). The role of the capability adapter is defined as an organizational role that aims to develop organizational capabilities for hybrid contexts through appropriate HRM systems and practices and foster the development of own hybrid capabilities. The data analysis identified themes such as HRM strategy (2a), HRM systems (2b), and HRM practices (2c). The review indicates that hybridization tendencies in organizational strategy (1d) generate impulses that lead to changes in the HRM strategy (2a) and structure affecting the alignment of HRM systems (2b) and HRM practices (2c); however, no precise distinction is made between strategy, systems, and practices in most articles.

Concerning HRM strategy (2a), Battilana et al. (2017) emphasize strategies of integration, differentiation, and combination, which consolidate the previous organizational strategies (1d). Management approaches that integrate are designed to combine different components. In contrast, differentiating approaches are designed to keep elements separated, like in a temporal or structural separation (e.g. Greenwood et al., 2011; Kraatz and Block, 2013; Pratt and Foreman, 2000). Recent studies describe management strategies that appear to apply a combination of integration and differentiation (Battilana et al., 2017). The hybrid literature indicates that these (HRM) strategies depend on the organizational hybridization type (1d); that is, how organizations focus on business or social aspects more or less intensively. The typology of Santos et al. (2015) here emphasizes that distinct types of hybrid organizations influence HRM strategy (2a). A hybridization type whose organizational strategy (1d) focuses on commercial activities should apply an HRM strategy (2a) that prioritizes staff with operational business expertise. In contrast, a hybridization type that follows a strategy of integration requires organizational members that combine business as well as social expertise skills, the "hybrid" profiles. 
Martin et al. (2016) provide insights on the integration of institutional logics in HRM systems (2b). They develop a new typology connecting HRM to different models of firmlevel corporate governance. Martin et al. (2016) identify two types of hybrid organizations - enlightened shareholder value and employee ownership. They suggest that the first type should be managed through a hybrid system approach that is high commitment/ collaborative and control/calculative oriented where structures, processes, and actor agency similarly reflect democratic principles of equality and involvement of all employees. They emphasize practices such as engaging more vulnerable, less value-adding, and scarce employees through inclusive, high-commitment HRM practices while maintaining an exclusive focus on high-value-adding employees in decision-making. For the second type, they propose a hybrid HRM approach involving high commitment/collaborative and control/calculative practices such as employer-provided training and development, and identification with the vision and purpose of the organization. They suggest practices to build employee commitment and quantifiable elements, such as incentive-based pay for performance. Additionally, the study by Ridder et al. (2012) in nonprofit commercialization reveals findings of the configuration of HRM systems. They demonstrate that nonprofits seek a specific configuration of HRM to confront the challenges they face in their internal and external environments. Applying the four HR architecture typesadministrative, motivational, strategic, and values-based HRM (see also Ridder and McCandless, 2010) - they illustrate how these types differ in their values integration, role of HRM in coping with external influences, HR principles and modes, as well as strategic and HR outcome goals. Their findings suggest that while HRM configuration is still influenced by HR orientation, a shift toward strategically oriented HRM systems is evident. Accordingly, the authors emphasize that nonprofits configure their HR practices to take a proactive approach to manage external constraints. These practices exhibit a financial performance orientation. However, Ridder et al. (2012) critically point out that an either-or orientation of value-based as well as purely strategy-oriented HRM systems in nonprofit organizations is problematic. Instead, they point to a third way, in which HRM is configured in a specific combination of the two orientations (Ridder et al., 2012). This third way could be considered a hybrid alignment of HRM systems. Roumpi et al. (2019) examine the design of HRM systems in social enterprises. In contrast to Ridder et al. (2012), they emphasize that HRM systems should be designed differentiated considering the ethics of care. Furthermore, Roumpi et al. (2019) suggest that the design of HRM systems based on ethics of care has a moderating effect on the impact of diverse workforce composition on organizational outcomes, such as tenure, financial performance, and social performance. This is because differentiated HRM systems capitalize on the uniqueness of the workforce possibly leading to superior organizational outcomes, which in turn reinforce the role of ethics of care leading to a virtuous circle (Roumpi et al., 2019).

The review results demonstrate that implementing organizational strategy, with the adoption of suitable HRM practices (2c), is essential in successfully attaining sustainability goals. As such, HRM practices are considered to have mediating functions. The mediating effect on achieving sustainability can differ depending on how these HRM practices are implemented. For example, Gulbrandsen et al. (2015) distinguish between weak/symbolic, contested, and strong HRM practices based on differences in their 
underlying goals and means. Weak practices contain shared goals that are theoretically formulated but lack operational status and strategic engagement (see also Fossestøl et al., 2015; Pache and Santos, 2013). New (hybrid) routines, and practices are created from contested and especially strong practices. This study indicates that hybridity can only lead to contested and strong HRM practices (2c) if hybrid goals do not merely remain as legitimation reasons in strategic decisions.

However, a negative example of aligning HRM practices can be found in the literature. Bruneel et al. (2016) demonstrate the influence of institutional logics on HRM structure. They show that an overemphasis on social logic and the increasing disregard of the commercial market logic led to the failure of an award-winning for-profit social enterprise called Metalcon. The focus on social logics brought an uneven HRM mix of employees and an underdeveloped internal organizational structure. Hence, the influence of conflicting logics may lead to a restructuring of SHRM practices in such a way that certain organizational goals can no longer be met adequately, leading to tensions and even organizational demise. This again shows that the alignment of HRM systems (2b) and HRM practices (2c) is essential in the execution of the organizational strategy (1d) and is an essential factor in preventing or managing tensions (1b) in hybrid contexts.

The analysis of the reviewed articles shows that the strategic and structural changes of SHRM require HRM practices that address paradoxical tensions (1b) such as belonging or learning. Numerous studies have identified HRM practices (2c), such as attraction, selection, and hiring of employees, as crucial in addressing tensions (1b). Hsieh et al. (2018) propose an attraction-selection-socialization model and emphasize effective HRM mechanisms in each process. Concerning selection, the findings of Imperatori and Ruta (2015) suggest that primary stakeholders should become part of the organizational workforce because of their role in supporting certain logics. Hsieh et al. (2018) further indicate that selection processes of social enterprises appear to mainly focus on sociallybased criteria such as personal values, traits, and the degree of consistency between the values of the candidates and the organization. Identity integration could be achieved through hiring or socialization practices that focus on the design of a hybrid organizational identity (Hsieh et al., 2018). Moreover, Napathorn's (2018) study shows that social enterprises frequently employ sub-stream or alternative recruitment channels, such as employee referral strategies, internship programs, and recruitment from vulnerable groups, to ensure that candidates have beliefs, attitudes, and experiences congruent with the objectives of the social enterprises. Moreover, Santos et al. (2015) suggest that hybrids close to pure commercial models should recruit employees with operational business expertise, while organizations that inherit an integrated structure should recruit employees with a hybrid profile. They propose that these employees can be recruited as blank slates without prior experience. This allows the hybrid organization to train and develop employees to become hybrid individuals, as substantiated by other studies (e.g. Battilana and Dorado, 2010; Dufays and Huybrechts, 2016). Moreover, Winkler and Portocarrero (2018) extend the typology of Santos et al. (2015) and demonstrate that the blended hybrid should recruit employees who are evaluated based on operational and social key performance indicators.

In addition to attraction and selection, the socialization of individuals is a key HRM practice (2c) within hybrid organizations. Organizational socialization is "the process by 
which an individual comes to appreciate the values, abilities, expected behaviors, and social knowledge essential for assuming an organizational role and for participating as an organizational member" (Louis, 1980: 229f). Ebrahim et al. (2014) emphasize that the socialization of managers and board members is critical for hybrid organizations. This implies that early socialization in a hybrid position or role can support paradoxical thinking (see paradoxical manager (1c). Ebrahim et al. (2014) further emphasize that hybrid organizations often cannot rely on an existing pool of job candidates whose professional backgrounds are congruent with the demands of their hybrid work context. Battilana and Dorado (2010) also address this by showing that hybrid organizations use alternative socialization and hiring strategies to balance the competing expectations of their institutional environments. Striking a balance between competing logics can be resolved by building a new organizational identity that transcends the organizational identity and logics of the respective institutions. As such, the hiring and socialization strategies employed by hybrid organizations are instrumental aspects of identity formation.

Furthermore, the findings indicate that HRM practices (2c), such as development and training, are approaches for developing internal hybrid professionals (Battilana and Dorado, 2010). Several studies show that HRM development and training practices support relevant managerial skills and socialization in hybrid contexts, empowering paradoxical managers (1c). Giacomelli et al. (2019) show that participation in managerial training programs in healthcare can support hybrid professionals with managerial skills and competencies and enhance their involvement in top management decision-making. McGivern et al. (2015) supplement this study by categorizing incidental and willing hybrids. Incidental hybrids are professionals who represent and protect traditional institutionalized professionalism and only temporarily act in hybrid roles. In contrast, willing hybrids describe those who engage with managers and managerialism, disrupting traditional professionalism. Thus, the training and development of managerial skills may support the socialization of hybrid professionals and managers. Burgess and Currie (2013) highlight early career socialization as a crucial factor supporting identity transition.

Furthermore, Smith et al. (2012) emphasize the development of the competencies of paradoxical managers (1c) to address tensions that emerge from the demands of competing logics. They emphasize competencies such as mindfully attending to distinctions between domains, embracing paradoxical thinking, or seeking synergies in decisionmaking. Al Taji and Bengo (2019) support this approach and show how managerial challenges such as mission drift or conflicting stakeholder demands are managed. Their results show that when people who work in social enterprises (i.e. founders, employees, volunteers) lack the necessary competencies and knowledge about the organization, the risk of mission drift and internal conflicts increases.

The findings indicate two functions of the capability adapter (B): evolution and revolution. The first is defined as a function that involves incremental selection, socialization, and development of employees. The results show that different organizational strategies require employees with certain skills. Organizations that focus on commercial activities require staff with business expertise, or organizations that inherit an integrated structure should recruit employees with a hybrid profile (Santos et al., 2015). Furthermore, healthcare organizations that operate hybrid structures need not only employees but also staff 
with managerial skills (Giacomelli et al., 2019). The capability adapter here intervenes to the extent such that practices implemented bring employees and managers with necessary skills into the organization, socializing, or developing them (Battilana and Dorado, 2010). Moreover, concerning the management of tensions, this review provides further indications for the role of the capability adapter. In terms of its evolutionary function, this role can ensure that tensions are reduced, as the focus is on the long-term and consistent development of skills. An overemphasis on certain logics, described in the study by Bruneel et al. (2016), could thus be avoided through careful development of capabilities.

In contrast, the findings indicate a revolution function, which is more disruptive. For example, McGivern et al. (2015) emphasize that to act in hybrid roles, managers are required to engage as willing hybrids. In this case, the capability adapter's role is to further promote these willing hybrids by developing hybrid capabilities and supporting paradoxical thinking. Moreover, early-career socialization, highlighted in the study by, Burgess and Currie (2013) is crucial for supporting identity transition. Here, the role of the capability adapter is to build capabilities that support readiness to change and flexibility resulting in a more comprehensive transition.

\section{HRM role configuration: Outcomes}

The last part of the figure is summarized under the term outcomes (3) and its corresponding functions that indicate the HRM role of the identification generator $(\mathrm{C})$ (see Figure 2). The role of the identification generator is defined as an organizational role that fosters hybrid mindsets to support the achievement of hybrid goals. The data analysis identified themes in terms of HRM outcomes (3a), organizational outcomes (3b), and societal outcomes (3c).

Results show that HRM outcomes (3a), such as employee turnover, are significant issues for hybrid organizations. The change or hybridization of organizational strategy (1d) is highlighted as a reason for employee turnover, as a change in HRM strategy (2a) influences HRM outcomes (3a), such as identification. For example, the study of Krøtel and Villadsen (2016) points out that public sector employees, socialized in public sector logics, are more likely to leave when their organization is exposed to higher degrees of privateness resulting in more profit-oriented internal pay structures and staffing patterns. A similar problem of hybrid organizations concerning the HRM outcome (3a) of identification is the HRM practice (2c) of acquisition. Ohana and Meyer (2010) provide insights. They show that individuals who desire to join nonprofit organizations are less money-oriented than those who want to enter for-profit firms. This study indicates that, although hybridization is necessary for nonprofit organizations to meet changing institutional demands, it leads to employees staying away because they cannot identify with the organization. Therefore, they do not consider joining the organization, resulting in HRM outcomes (3a), such as workforce shortage. However, the study by Moses and Sharma (2020) reveals different findings. Applying an institutional logics lens, they propose that market logic and community logic-driven HR practices influence the organization's ability to acquire and retain HR. They indicate that while 
market logic-driven HR practices help with HR acquisition, community logic-driven HR practices help with HR retention. Interestingly, the study emphasizes that social enterprises should focus less on their social mission and more on market logics to attract talents. HR practices linked to community logic act as motivators for existing employees, as they reinforce commitment to the social mission. Furthermore, this leads to improved long-term performance (Moses and Sharma, 2020). There are similarities with the previous findings regarding the application of hybrid or differentiated HRM systems (Ridder et al., 2012). In addition, the previous findings of an outside-in perspective (Aust et al., 2020; Dyllick and Muff, 2016) can be confirmed as a focus or alignment on market logic in hybrid organizations that have a positive effect on HRM outcomes (3a), such as retention. Nevertheless, the implementation of hybrid systems and practices should be treated with caution, as they have a significant impact on the identification of employees (Hsieh et al., 2018).

Thus, the review results show that in terms of HRM outcomes especially in hybrid organizations, the SHRM role of an identification generator (C) is required (see Figure 2). Regarding the importance of identification concerning turnover and the attraction of potential employees, the role of the identification generator is implied by involvement and signaling functions. Regarding the signaling function, the SHRM literature suggests that HRM practices can be viewed as signaling and communication mechanisms regarding expected, valued, and rewarded behaviors (Bowen and Ostroff, 2004). The more complex and inconsistent these signals are, the less observable these behaviors will be, leading to divergent interpretations of the same practice (Roehl, 2019). Transferring this to the role of the identification generator (C), the signal function includes applying HRM practices such as attraction, selection, and hiring, which indicate the organizational culture and attracts like-minded employees (Albert and Whetten, 1985).

The results show that HRM outcomes (3a), such as commitment and job satisfaction, influence turnover tendencies. Ohana and Meyer (2010) indicate that job satisfaction has a greater impact on turnover intentions than commitment. They emphasize that to support the HRM outcome (3a) job satisfaction, HRM practices (2c), such as involvement and job enrichment, might be of importance for hybrid organizations. Zhang et al. (2018) show that perceived empowerment-oriented HRM practices (2c) could increase employees' commitment by enhancing their identification motivation. Similarly, findings suggest that HRM practices (2c) for increased HRM outcome (3a) of identification are important in hybrid contexts, as multiple values and identities can be an obstacle for individuals to identify with the organization and may result in belonging tension (Smith et al., 2013). Existing research on identification emphasizes that it arises when members recognize consistency between their own and their organization's identities (Ashforth et al., 2008), which seems to be associated with lower employee turnover (Mael and Ashforth, 1995), organizational commitment (Foreman and Whetten, 2002), information sharing, and job satisfaction (Besharov, 2014). The high-involvement work processes that affect employee well-being shows the importance of the involvement function in the role of identification generator (C) (Boxall and Macky, 2014). 
The results show that a common and shared organizational identity is an essential organizational outcome ( $3 \mathrm{~b}$ ), which should be supported by suitable HRM practices. Hsieh et al. (2018) suggest that social enterprises need to manage their hybrid organizational identities and embed a new common organizational identity (3b) into members' daily work through HRM practices (2c) such as attraction, selection, and socialization to foster HRM outcomes (3a) of identification, and organizational outcomes (3b), such as sustainable hybridization.

The results also show the emotional exhaustion of employees as a further negative HRM outcome (3a) in hybrid organizations. This outcome can be mediated by HRM outcomes, such as job satisfaction and commitment. Melnik et al. (2013) show that satisfaction at work is negatively correlated with perceptions of fatigue and pressure. In this regard, Conway et al. (2016) highlight HRM practices (2c), such as employee voice mechanisms, which may act as a resource both in enhancing the commitment of employees and counterbalancing the demands presented by such HRM systems (2b) like performance management systems, thus reducing HRM outcomes (3c), such as emotional exhaustion and its effects. Additionally, the result implies that if negative HRM outcomes of hybridization, such as turnover and emotional exhaustion, can be reduced, other HRM outcomes can be accelerated by HRM practices such as building competencies and skills. This is where the involvement function of the identification generator is important. In this context, involvement refers to the early integration and participation of employees (e.g. in HRM practices such as development and training) to avoid emotional exhaustion or the emergence of belonging tensions.

The results indicate that HRM outcomes have an impact on organizational and societal outcomes. Powell et al. (2019) indicate that HRM outcomes (3a), such as a hybrid workforce with specific competencies and skills, are crucial for a hybrid organization's ability to simultaneously achieve organizational outcomes (3b), such as sustainability and performance outcomes, thus creating societal outcomes $(3 \mathrm{c})$. In the case of a public service organization, Powell et al. (2019) emphasize that a hybrid workforce is composed of employees skilled in the service they are delivering, rather than just having a social care background. Thus, HRM hiring and development practices $(2 \mathrm{c})$ that foster HRM outcomes (3a) of (special or hybrid) competencies and skills support the composition of a hybrid workforce. This workforce further enhances organizational outcomes (3b), such as service quality and financial performance (Powell et al., 2019). Ren and Jackson (2020) provide detailed insights into the influences of competencies as HRM outcomes (3a) on organizational outcomes (3b), such as sustainability. They introduce the concept of HRM institutional entrepreneurship, which defines "the actions taken by HRM professionals acting as individuals or as a group to leverage resources such as their skills, knowledge and social capital as well as the organization's HRM system in order to change organizational norms, rules, routines and values" (Ren and Jackson, 2020: 3). Their study indicates that to contribute to sustainability outcomes or sustainable hybridization, HRM professionals need to understand and manage paradoxes (Smith and Lewis, 2011). Overall, the results show that sustainable hybridization allows hybrid organizations to exist in the long term, making a substantial societal contribution. According to the conceptual statements of Haigh et al. (2015) sustainable hybrid organizations can serve as incubators for new practices and be used to create sustainable 


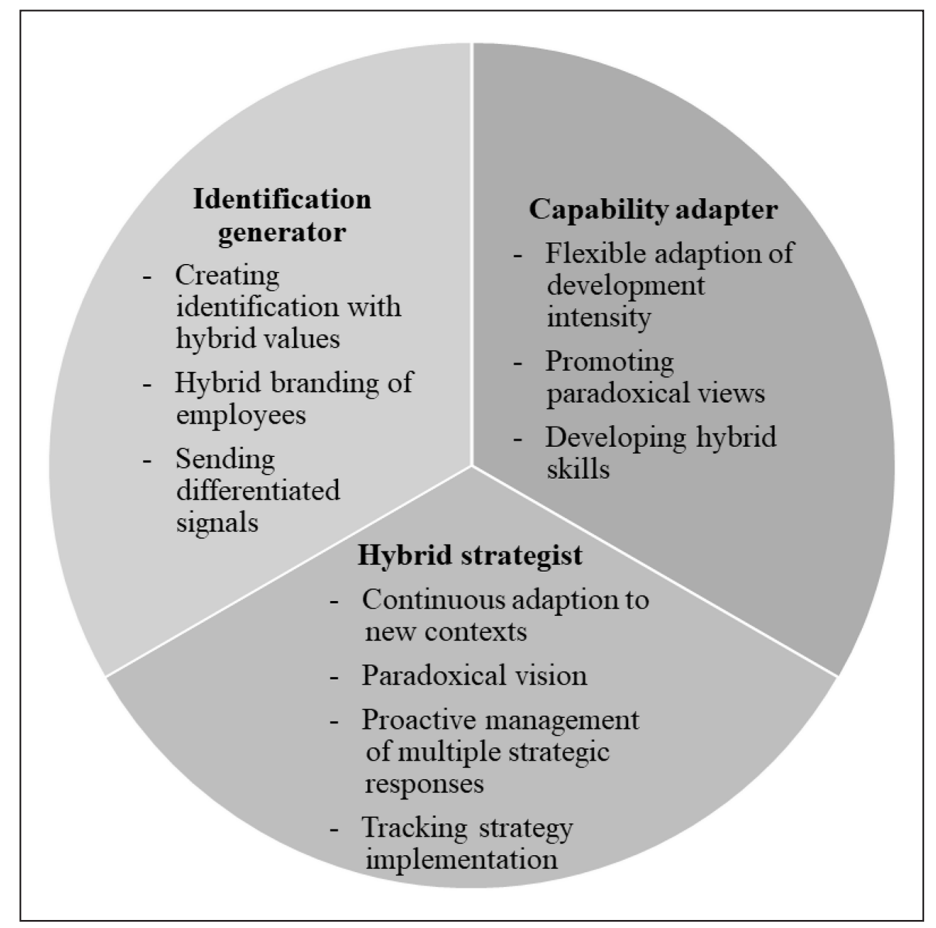

Figure 3. HRM roles for addressing tensions and contributing to sustainability in hybrid organizations.

social value. Moreover, the emphasis on sustainable hybridization can create organizations that thrive (Smith and Besharov, 2019), implying societal outcomes (3c) of societal well-being.

\section{Discussion of HRM roles in hybrid organizations}

The previous section derived three HRM roles in hybrid organizations-hybrid strategist, capability adapter, and identification generator (see Figure 2). The following section presents a discussion of the proposed HRM roles in terms of how they broaden existing HRM roles and contribute to sustainability goals as well as the management of tensions (see Figure 3).

\section{The role of the hybrid strategist}

The first HRM role refers to the determinants in hybrid contexts. This HRM role extends the roles of the strategic business partner (Ulrich, 1997; Ulrich et al., 2013) and focuses on the facilitation of achievement of environmental, social, and economic goals (Christina et al., 2017; Haddock-Millar et al., 2016). The hybrid strategist's first contribution is its continuous adaption to new contexts. In Ulrich's (1997) definition, strategic partners are 
senior or key HRM professionals assigned to a business unit to help managers develop and execute strategies. In recent versions, strategic partners have also been described as strategic positioners and change agents (Ulrich et al., 2012). However, although the business partner model provides answers to HRM tensions, researchers argue that the ongoing change in the business environment requires HRM roles to adapt to the new contexts (Ulrich and Dulebohn, 2015). This rigid focus has led researchers to emphasize HRM roles that focus on facilitating the achievement of environmental and social goals (Haddock-Millar et al., 2016) and the integration of conflicting demands from a one-pole perspective (Gerpott, 2015). Furthermore, Gerpott (2015) suggested cultivating a paradoxical vision to support both sustainability and change. She further emphasizes the service that HRM should provide to various stakeholder groups, considering the organizational context. Now, one could argue that by emphasizing these features of the newer HRM roles on sustainability goals and paradoxical thinking, the tasks of the strategist role has already been addressed.

However, the hybrid strategist also differs from the newer roles in that it adopts a paradoxical outside-in perspective that does not stem from a business perspective, but rather a hybrid perspective. In other words, paradoxical vision is aimed at integrating not only sustainability goals into a profit-oriented context but also profit-oriented strategies into a socially driven organization. In the third sector, requirements are more likely to be made for more efficient management (Dart, 2004). Key stakeholders such as society, donors, or political committees mobilize logics in a differentiated way and then are objects of micro-negotiations in HRM decisions (Battilana and Dorado, 2010; Desmarais et al., 2019). If stakeholder demands and logics are taken up in the respective organizational structures and HRM strategy they create (paradoxical) tensions and if not properly addressed, will cause vicious cycles (Putnam et al., 2016). The task of deriving appropriate responses to multiple demands and tensions, making strategic decisions, and interpreting the logics that facilitate sustainability goals is dependent on how the (paradoxical) manager interprets the logics (Currie and Spyridonidis, 2016).

This interpretation context highlights the origin of the hybrid strategist, as the support and advisory functions (see Figure 2) of this role are derived from the (paradoxical) manager, working in both directions - integrating sustainability demands in profit organizations and profit-oriented structures and practices in social organizations. These functions imply that hybrid strategists can cultivate a paradoxical vision starting from business and social perspectives, by identifying and understanding key contextual factors that explain possible tensions. In this sense, the hybrid strategist adopts an outside-in perspective (Aust et al., 2020; Dyllick and Muff, 2016). Predicting potential tensions from both perspectives (profit and social) enables the hybrid strategist to advice on the proactive management of multiple strategic responses to serve various stakeholder groups. Moreover, the support function facilitates a starting point from both perspectives (profit and social) indicating that the hybrid strategist serves various stakeholder groups in designing strategic responses that address tensions to achieve long-term solutions and promote virtuous cycles (Putnam et al., 2016).

The last distinction, derived from established HRM roles is the actual implementation of systems and practices. The review shows that with the political orientation function (see Figure 2), the hybrid strategist ensures the implementation of profit and 
social-oriented systems and practices by promoting managers' strategic decisions. Moreover, tracking strategy implementation, strategies, such as symbolic compliance, are avoided ensuring that hybridity does not remain in the realm of organizational strategy (Pache and Santos, 2013).

\section{The role of the capability adapter}

The second HRM role refers to the content in hybrid contexts. The capability adapter develops the capabilities for change or hybridization through training and development practices that are designed to create and develop knowledge, skills, and competencies required to achieve hybrid goals (Guerci et al., 2016; Haddock-Millar et al., 2016). The results indicate two functions entailed in this role-evolution and revolution (see Figure 2). While the evolution function is to design a continuous adaptation of capabilities to hybrid requirements, the revolution function implies a comprehensive or radical adaption to change. In this regard, the capability adapter combines the roles of the capability builder and the change champion defined by Ulrich et al. (2013) to the hybrid context. They emphasize that as a capability builder, an effective HR professional melds individual abilities into an effective and strong organization by helping to define and build critical organizational capabilities, while the change champion initiate and sustain change (Ulrich et al., 2013).

The review, shows that hybrid organizations require employees who possess the necessary competencies and capabilities to pursue social and economic goals (Battilana and Dorado, 2010). As such, different hiring, development, and socialization practices are implemented (Hsieh et al., 2018; Pache and Santos, 2010). The capability adapter is distinguished from the roles of capability builder and change champion by the ability to embrace the both-and function; that is, they can act in either evolutionary or revolutionary ways to build (hybrid) organizational capabilities and to sustain change. This flexible adaption of development intensity is particularly important as hybridization can lead to tensions that may arise through HR activities, such as training and development (Melnik et al., 2013). In terms of its evolutionary function, the role of the capability adapter can ensure that tensions are reduced, as the role focuses on a long-term and consistent development of skills to avoid a radical change by an overemphasis on certain logics as described in the study by Bruneel et al. (2016). However, the revolution function requires the capability adapter to ensure the application of new or contrary HRM practices for example, promoting paradoxical views and developing hybrid skills initiating significant change with regard to existing work processes and routines.

In this regard, the concept of dynamic capabilities (Teece, 2007; Teece et al., 1997) may provide valuable insights. Dynamic capabilities are substantiated by organizational routines and management skills. They are the capability of the organization to integrate, build, and reconfigure internal competencies to address or create change in the business environment (Teece, 2007; Teece et al., 1997). Teece (2007) defines dynamic capabilities in terms of sensing, seizing, and reconfiguration. Sensing includes systems to learn, sense, filter, and shape opportunities. Seizing describes how sensed opportunities are managed and reconfiguration refers to the ability to recombine assets and organizational structures that match the organization's internal processes, new seized processes and practices. 
Thus, by fulfilling the role of a capability adapter in applying both evolution and revolution functions, the sensing approach emphasizes that HRM professionals need to be aware of the required employee skills and competencies to pursue dual strategies. Here, sustainable HRM competencies such as integrating short- and long-term purposes or raising awareness of the accountability of HRM for the impact of decisions might be helpful (Aust et al., 2020). Furthermore, the skills to recognize and accept interrelated demands and paradoxical tensions are required for the management of the organization's workforce. Hybrid managers can interpret dual logics and enact strategic decisions. HRM can hire suitable people or support the development of existing personnel regarding hybrid roles and hybrid thinking (Currie and Spyridonidis, 2016; McGivern et al., 2015). Moreover, to support the integration of social goals, stakeholders embedded in supporting those particular goals should become part of the workforce structure (Imperatori and Ruta, 2015). Capability adapters should seize the selection and implementation of training and development methods, which promote hybrid thinking or special skills (Giacomelli et al., 2019) to reduce the risk of internal conflicts (Al Taji and Bengo, 2019). HR professionals need (hybrid) reconfiguration skills to combine new and old HRM practices. Simultaneously, HR professionals must be conscious that the combination of HR practices, due to different performance and sustainability goals, may create tensions and should consider how to redesign business practices to match new perspectives and goals, with minimal tension, to achieve sustainability (Aust et al., 2020).

\section{The role of the identification generator}

The third HRM role refers to the outcomes in hybrid contexts. This role adopts the implementation of HRM practices that lead to sustainable (HRM) outcomes by creating identification with hybrid values, thus mitigating turnover tendencies. Identification arises when members perceive their own and their organization's identities to be consistent (Ashforth et al., 2008). Identity theory suggests that the identification of employees with the values of the organization contributes to commitment, job satisfaction, and engagement, which further reduces employee turnover (Battilana and Dorado, 2010; Napathorn 2018). These two functions define the role of the identification generatorsignaling and involvement (see Figure 2). In hybrid organizations, the signaling function may be important when applying HRM practices such as attracting and hiring. This is because divergent employee identities can cause tension among members (Hsieh et al., 2018). Thus, attracting employees with congruent identities and values may facilitate the formation of a common hybrid identity. The involvement function includes HR practices, such as job enrichment and employee voice that influence HRM outcomes, such as job satisfaction, and reduces turnover tendencies.

It can be assumed that the identification generator is a modified employer brander. Backhaus and Tikoo (2004: 501) note that "employer branding represents a firm's efforts to promote, both within and outside the firm, a clear view of what makes it different and desirable as an employer." Furthermore, research notes that organizations with a "good" employer brand will attract more talented applicants (Cable and Turban, 2003). Employer branding also helps to retain talented individuals, build trust in leadership, and develop 
stronger bonding ties through its impact on individual, team, and organizational engagement (Gittell et al., 2010). Attracting and retaining talented employees is an essential aspect of organizational sustainability, as it reduces hiring and training costs and creates a certain level of stability in organizations. As such, the identification generator reflects the future HR role of talent acquisition described by Ulrich and Dulebohn (2015). However, what distinguishes the identification generator is that it captures how organizations that pursue hybrid goals and inherit hybrid identities can "brand" employees implying the ability of hybrid branding of employees.

Moreover, the identification generator addresses how successful employer branding can avoid belonging tensions arising when organizational goals change. Conversely, the identification generator applies HRM practices that send clear signals to exclude employees who may be unsuitable for the organization or who do not intend to stay in the long term., thereby promoting sustainability. If required, signals transmitted through HRM practices adapt a hybrid strategy, for example, integration or combination (e.g. Battilana and Dorado, 2010). The ability to create identification to a hybrid strategy by sending differentiated signals may also be beneficial for the subsequent socialization of employees within the organization because they already inherit pre-socialized hybrid values (Hsieh et al., 2018). Conversely, the identification generator addresses belonging tensions with existing employee. While new employees are socialized into an organizational identity that is appealing to them, existing employees know a different version of this organizational identity. Moreover, new demands are placed on existing employees; for example, changes in their daily tasks or training for the development of new competencies. This often leads to employees being overburdened, emotional exhaustion, and, in the worst case, leaving the organization (Conway et al., 2016; Ohana and Meyer, 2010). Thus, the sustainability-generating character of the involvement function consists of high-involvement HRM practices, such as compensation and communication (Arthur, 1994). Moreover, it can comprise of HR practices that are linked to a social or community logic. These practices act as a motivator for existing employees, increasing HR retention and reinforcing employee commitment to the social mission, leading to engagement and improved long-term performance (Moses and Sharma, 2020). Hence, the signal and involvement functions of the identification generator support organizational sustainability goals (Aust et al., 2020) by addressing and socializing matching employees using flexible and differentiated signals and reducing belonging tensions through the integration of existing employees.

\section{Conclusion}

Over the last few decades, environmental changes have led to a transformation in SHRM and its organizational roles. There is a growing demand for HRM roles that contribute to the achievement of sustainability and the management of emerging tensions (Aust et al., 2020; Keegan et al., 2019). However, the gap until date is that the majority of HRM roles that are currently in operation still focus on a profit orientation. Moreover, although paradoxical approaches emphasize that HRM roles require the adoption of paradoxical thinking to manage tensions, we still lack knowledge about how this adoption occurs. Hence, despite some theoretical and empirical progress in redesigning HRM roles, the 
consideration of HRM roles from a hybrid perspective has been neglected. This is critical, as HRM roles that can address hybrid contexts are particularly relevant for HR practitioners as organizations increasingly hybridize.

Addressing the research question of how HRM roles are configured in hybrid organizations, this article draws on insights obtained through a systematic review. Studying HRM in hybrid organizations provide new avenues into the configuration of future HRM roles and functions, contributing to the development of sustainability goals and tension management.

This article proposes three HRM roles and related functions to supplement previous findings. Adopting an outside-in perspective, the organizational role of the hybrid strategist is proposed. This role includes a political orientation function in which key contextual factors are identified and transferred to the strategy. Furthermore, the hybrid strategist includes an advisory and support function, which assists in strategic management decisions, ensuring the transfer of strategic decisions into the HRM strategy and practices. Moreover, the role of the capability adapter is introduced. With its evolution and revolution function, this role involves building and implementing HRM practices that achieve sustainability goals by creating and developing specific (hybrid) competencies, and addressing the tensions generated by this development. Finally, the organizational role of the identification generator is proposed. This role includes the development of organizational identity, and the support for sustainable hybridization. This is supported by a signaling function aimed at attracting potential employees who have similar values and can easier be socialized into the organization. The involvement function includes addressing belonging tensions.

Mapping the research landscape of HRM in hybrid organizations and proposing three HRM roles this article contributes in theoretical and practical terms. Theoretically, existing paradox-theoretical approaches in the HRM literature regarding to the requirements for HRM to contribute to sustainable or hybrid goals are addressed. Additionally, the current discussion on tensions arising from the integration of divergent goals is tackled and supplemented by insights from the hybrid literature. Finally, based on the findings of the literature review, three HRM roles are proposed that supplement and extend existing roles. Based on a hybrid context, these roles provide detailed insights what HRM functions are required to contribute to sustainability and the management of tensions. Thus, the proposed roles lay the foundation for future HRM roles that create value by ensuring that services HRM offers inside the organization are aligned with expectations outside. Moreover, the HRM roles inherit a configuration able to adapt paradoxical thinking to handle tensions simultaneously. As such in practical terms, the proposed HRM roles provide guidance for HR practitioners on how to manage sustainability goals and address tensions in hybrid contexts. Taken together, the proposed HRM roles provide a further step to enhance existing HRM roles (Ulrich, 1997; Ulrich and Dulebohn, 2015). However, further research is required to specify these roles and their interrelationships and apply them empirically. Moreover, it is important to clarify which structural conditions are required to support the successful implementation and application of these roles. Finally, it should be investigated whether certain HRM roles are of greater relevance in different hybridization contexts and to what extent the roles of the hybrid strategist, capability adapter, and identification generator are mutually reinforcing. 


\section{Declaration of conflicting interests}

The authors have no relevant financial or non-financial interests to disclose.

\section{Funding}

The author(s) received no financial support for the research, authorship, and/or publication of this article.

\section{ORCID iD}

Anja Belte (iD https://orcid.org/0000-0001-8651-8887

\section{Note}

1. Q1 to Q4 refer to journal ranking quartiles within a subdiscipline using the SCImago Journal Rank (SJR) citation index. Thus, a first quartile journal (Q1) has an SJR in the top $25 \%$ of journals for at least one of its classified subdisciplines. Q2 is occupied by journals in the $25 \%$ to $50 \%$ group and Q3 is occupied by journals in the $50 \%$ to $75 \%$ group.

\section{References}

Albert S and Whetten D (1985) Organisational identity. In: Cummings LL and Staw BM (eds) Research in Organisational Behaviour. Greenwich, CT: JAI Press, pp.263-295.

Al Taji FNA and Bengo I (2019) The distinctive managerial challenges of hybrid organizations: Which skills are required? Journal of Social Entrepreneurship 10(3): 328-345.

Alvehus J (2018) Conflicting logics? The role of HRM in a professional service firm. Human Resource Management Journal 28(1): 31-44.

Arthur JB (1994) Effects of human resource systems on manufacturing performance and turnover. Academy of Management Journal 37(3): 670-687.

Ashforth BE, Harrison SH and Corley KG (2008) Identification in organizations: An examination of four fundamental questions. Journal of Management 34(3): 325-374.

Ashforth BE and Reingen PH (2014) Functions of dysfunction. Administrative Science Quarterly 59(3): 474-516.

Aust I, Brandl J, Keegan A, et al. (2017) Tensions in managing human resources introducing a paradox framework and research agenda. In: Jarzabkowski P, Lewis MW, Smith WK, et al. (eds) The Oxford Handbook of Organizational Paradox. Oxford: Oxford University Press, pp.413-433.

Aust I, Matthews B and Muller-Camen M (2020) Common good HRM: A paradigm shift in sustainable HRM? Human Resource Management Review 30(3): 100705.

Backhaus K and Tikoo S (2004) Conceptualizing and researching employer branding. Career Development International 9(4-5): 501-517.

Bakker AB and Demerouti E (2007) The job demands-resources model: State of the art. Journal of Managerial Psychology 22(3): 309-328.

Battilana J, Besharov M and Mitzinneck B (2017) On hybrids and hybrid organizing: A review and roadmap for future research. In: Greenwood R, Oliver C, Lawrence TB, et al. (eds) The SAGE Handbook of Organizational Institutionalism. Thousand Oaks, CA: SAGE, pp.128-162.

Battilana J and Dorado S (2010) Building sustainable hybrid organizations: The case of commercial microfinance organizations. Academy of Management Journal 53(6): 1419-1440. 
Battilana J and Lee M (2014) Advancing research on hybrid organizing - Insights from the study of social enterprises. The Academy of Management Annals 8(1): 397-441.

Battilana J, Sengul M, Pache A-C, et al. (2015) Harnessing productive tensions in hybrid organizations: The case of work integration social enterprises. Academy of Management Journal 58(6): 1658-1685.

Beer M, Bert S, Lawrence P, et al. (1985) Human Resource Management: A General Manager's Perspective: Text and Cases. New York, NY: Free Press.

Beer M, Boselie P and Brewster C (2015) Back to the future: Implications for the field of HRM of the multistakeholder perspective proposed 30 years ago. Human Resource Management 54(3): 427-438.

Besharov ML (2014) The relational ecology of identification: How organizational identification emerges when individuals hold divergent values. Academy of Management Journal 57(5): $1485-1512$.

Besharov ML and Smith WK (2014) Multiple institutional logics in organizations: Explaining their varied nature and implications. Academy of Management Review 39(3): 364-381.

Bowen DE and Ostroff C (2004) Understanding HRM-firm performance linkages: The role of the "Strength" of the HRM system. Academy of Management Review 29(2): 203.

Boxall P and Macky K (2014) High-involvement work processes, work intensification and employee well-being. Work Employment \& Society 28(6): 963-984.

Bruneel J, Moray N, Stevens R, et al. (2016) Balancing competing logics in for-profit social enterprises: A need for hybrid governance. Journal of Social Entrepreneurship 7(3): 263-288.

Burgess N and Currie G (2013) The knowledge brokering role of the hybrid middle level manager: The case of healthcare. British Journal of Management 24: S132-S142.

Cable DM and Turban DB (2003) The value of organizational reputation in the recruitment context: A brand-equity perspective. Journal of Applied Social Psychology 33(11): 2244-2266.

Christina S, Dainty A, Daniels K, et al. (2017) Shut the fridge door! HRM alignment, job redesign and energy performance. Human Resource Management Journal 27(3): 382-402.

Conway E, Fu N, Monks K, et al. (2016) Demands or resources? The relationship between HR practices, employee engagement, and emotional exhaustion within a hybrid model of employment relations. Human Resource Management 55(5): 901-917.

Currie G and Spyridonidis D (2016) Interpretation of multiple institutional logics on the ground: Actors' position, their agency and situational constraints in professionalized contexts. Organization Studies 37(1): 77-97.

Dart R (2004) Being "business-like" in a non-profit organization: A grounded and inductive typology. Nonprofit and Voluntary Sector Quarterly 33(2): 290-310.

Denyer D and Tranfield D (2009) Producing a systematic review. In: Buchanan DA and Bryman A (eds) Organizational Research Methods. Thousand Oaks, CA: SAGE, pp.671-689.

Desmarais C, Dubouloz S and Bichon A (2019) Hybridisation of human resources management practices: The case of local government in France. International Review of Administrative Sciences. DOI: 10.1177/0020852319864151

Doherty B, Haugh H and Lyon F (2014) Social enterprises as hybrid organizations: A review and research agenda. International Journal of Management Reviews 16(4): 417-436.

Dufays F and Huybrechts B (2016) Where do hybrids come from? Entrepreneurial team heterogeneity as an avenue for the emergence of hybrid organizations. International Small Business Journal 34(6): 777-796.

Dyllick T and Muff K (2016) Clarifying the meaning of sustainable business. Organization \& Environment 29(2): 156-174.

Ebrahim A, Battilana J and Mair J (2014) The governance of social enterprises: Mission drift and accountability challenges in hybrid organizations. Research in Organizational Behavior 34: 81-100. 
Ehnert I (2009) Sustainable Human Resource Management. Heidelberg: Physica-Verlag HD.

Ehnert I (2014) Paradox as a lens for theorizing sustainable HRM. In: Ehnert I, Harry W and Zink KJ (eds) Sustainability and Human Resource Management. Berlin, Heidelberg: Springer, pp.247-271.

Farndale E and Paauwe J (2018) SHRM and context: Why firms want to be as different as legitimately possible. Journal of Organizational Effectiveness People and Performance 5(3): 202-210.

Foreman P and Whetten DA (2002) Members' identification with multiple-identity organizations. Organization Science 13(6): 618-635.

Fossestøl K, Breit E, Andreassen TA, et al. (2015) Managing institutional complexity in public sector reform: Hybridization in front-line service organizations. Public Administration 93: 290-306.

Friedland R and Alford RR (1991) Bringing society back in: Symbols, practices, and institutional contradictions. In: Powell WW and DiMaggio PJ (eds) The New Institutionalism in Organizational Analysis. Chicago, IL: University of Chicago Press, pp.232-263.

Gerpott FH (2015) The right strategy? Examining the business partner Model's functionality for resolving human resource management tensions and discussing alternative directions. German Journal of Human Resource Management: Zeitschrift für Personalforschung 29 (3-4): 214-234.

Giacomelli G, Ferré F, Furlan M, et al. (2019) Involving hybrid professionals in top management decision-making: How managerial training can make the difference. Health Services Management Research 32(4): 168-179.

Gioia DA, Corley KG and Hamilton AL (2013) Seeking qualitative rigor in inductive research. Organizational Research Methods 16(1): 15-31.

Gittell JH, Seidner R and Wimbush J (2010) A relational model of how high-performance work systems work. Organization Science 21(2): 490-506.

Glynn MA (2000) When cymbals become symbols: Conflict over organizational identity within a symphony orchestra. Organization Science 11(3): 285-298.

Glynn MA, Hood EA and Innis BD (2020) Taking hybridity for granted: Institutionalization and hybrid identification. In: Besharov ML and Mitzinneck BC (eds) Organizational Hybridity: Perspectives, Processes, Promises. Bingley: Emerald Publishing, pp.53-72.

Graen GB and Uhl-Bien M (1995) Relationship-based approach to leadership: Development of leader-member exchange (LMX) theory of leadership over 25 years: Applying a multi-level multi-domain perspective. The Leadership Quarterly 6(2): 219-247.

Greenwood R, Raynard M, Kodeih F, et al. (2011) Institutional complexity and organizational responses. The Academy of Management Annals 5(1): 317-371.

Guerci M, Longoni A and Luzzini D (2016) Translating stakeholder pressures into environmental performance - The mediating role of green HRM practices. The International Journal of Human Resource Management 27(2): 262-289.

Gulbrandsen M, Thune T, Borlaug SB, et al. (2015) Emerging hybrid practices in public-private research centres. Public Administration 93(2): 363-379.

Haddock-Millar J, Sanyal C and Müller-Camen M (2016) Green human resource management: A comparative qualitative case study of a United States multinational. The International Journal of Human Resource Management 27(2): 192-211.

Haigh N, Walker J, Bacq S, et al. (2015) Hybrid organizations: Origins, strategies, impacts, and implications. California Management Review 57(3): 5-12.

Hsieh Y-C, Weng J and Lin T (2018) How social enterprises manage their organizational identification: A theoretical framework of identity management approach through attraction, selection, and socialization. The International Journal of Human Resource Management 29(20): $2880-2904$. 
Imperatori B and Ruta DC (2015) Designing a social enterprise. Social Enterprise Journal 11(3): 321-346.

Jay J (2013) Navigating paradox as a mechanism of change and innovation in hybrid organizations. Academy of Management Journal 56(1): 137-159.

Keegan A, Brandl J and Aust I (2019) Handling tensions in human resource management: Insights from paradox theory. German Journal of Human Resource Management: Zeitschrift für Personal forschung 33(2): 79-95.

Kraatz MS and Block ES (2013) Organizational implications of institutional pluralism. In: Greenwood R and Royston R (eds) The Sage Handbook of Organizational Institutionalism. Los Angeles, CA: SAGE, pp.243-275.

Kramar R (2014) Beyond strategic human resource management: Is sustainable human resource management the next approach? The International Journal of Human Resource Management 25(8): 1069-1089.

Krøtel SML and Villadsen AR (2016) Employee turnover In hybrid organizations: The role of public sector socialization and organizational privateness. Public Administration 94(1): 167-184.

Lee M and Battilana J (2013) How the zebra got its stripes: Imprinting of individuals and hybrid social ventures. Harvard Business School working paper no. 14-005, July. DOI: 10.2139/ ssrn. 2291686.

Litrico J-B and Besharov ML (2019) Unpacking variation in hybrid organizational forms: Changing models of social enterprise among nonprofits, 2000-2013. Journal of Business Ethics 159(2): 343-360.

Llewellyn S (2001) 'Two-Way windows': Clinicians as medical managers. Organization Studies 22(4): 593-623.

Louis MR (1980) Surprise and sense making: What newcomers experience in entering unfamiliar organizational settings. Administrative Science Quarterly 25(2): 226-251.

McGivern G, Currie G, Ferlie E, et al. (2015) Hybrid manager-professionals' identity work: The maintenance and hybridization of medical professionalism In managerial contexts. Public Administration 93(2): 412-432.

Mael FA and Ashforth BE (1995) Loyal from day one: Biodata, organizational identification, and turnover among newcomers. Personnel Psychology 48(2): 309-333.

Mair J, Mayer J and Lutz E (2015) Navigating institutional plurality: Organizational governance in hybrid organizations. Organization Studies 36(6): 713-739.

Martin G, Farndale E, Paauwe J, et al. (2016) Corporate governance and strategic human resource management: Four archetypes and proposals for a new approach to corporate sustainability. European Management Journal 34(1): 22-35.

Melnik E, Petrella F and Richez-Battesti N (2013) Does the professionalism of management practices in nonprofits and for-profits affect job satisfaction? The International Journal of Human Resource Management 24(6): 1300-1321.

Meyer JW and Rowan B (1977) Institutionalized organizations: Formal structure as myth and ceremony. American Journal of Sociology 83(2): 340-363.

Moses A and Sharma A (2020) What drives human resource acquisition and retention in social enterprises? An empirical investigation in the healthcare industry in an emerging market. Journal of Business Research 107: 76-88.

Napathorn C (2018) How do social enterprises recruit workers? The case of social enterprises in Thailand. Journal of Asia Business Studies 12(4): 508-532.

Newman A, Mayson S, Teicher J, et al. (2015) Special issue of International Journal of Human Resource Management: Recruiting, managing and rewarding workers in social enterprises. The International Journal of Human Resource Management 26(14): 1907-1909. 
Ohana M and Meyer M (2010) Should I stay or should I go now? Investigating the intention to quit of the permanent staff in social enterprises. European Management Journal 28(6): 441-454.

Pache A-C and Santos F (2010) When worlds collide: The internal dynamics of organizational responses to conflicting institutional demands. Academy of Management Review 35(3): 455-476.

Pache A-C and Santos F (2013) Inside the hybrid organization: Selective coupling as a response to competing institutional logics. Academy of Management Journal 56(4): 972-1001.

Perkmann M, McKelvey M and Phillips N (2019) Protecting scientists from Gordon Gekko: How organizations use hybrid spaces to engage with multiple institutional logics. Organization Science 30(2): 298-318.

Podgorodnichenko N, Edgar F and McAndrew I (2020) The role of HRM in developing sustainable organizations: Contemporary challenges and contradictions. Human Resource Management Review 30(3): 100685.

Powell M, Gillett A and Doherty B (2019) Sustainability in social enterprise: Hybrid organizing in public services. Public Management Review 21(2): 159-186.

Powell WW and DiMaggio PJ (1991) The New Institutionalism in Organizational Analysis. Chicago, IL: Chicago University Press.

Pratt MG and Foreman PO (2000) Classifying managerial responses to multiple organizational identities. Academy of Management Review 25(1): 18.

Putnam LL, Fairhurst GT and Banghart S (2016) Contradictions, dialectics, and paradoxes in organizations: A constitutive approach. The Academy of Management Annals 10(1): 65-171.

Reay T and Hinings CR (2009) Managing the rivalry of competing institutional logics. Organization Studies 30(6): 629-652.

Ren S and Jackson SE (2020) HRM institutional entrepreneurship for sustainable business organizations. Human Resource Management Review 30(3): 100691.

Ridder H-G and McCandless A (2010) Influences on the architecture of human resource management in nonprofit organizations: An analytical framework. Nonprofit and Voluntary Sector Quarterly 39(1): 124-141.

Ridder H-G, Piening EP and Baluch AM (2012) The third way reconfigured: How and why nonprofit organizations are shifting their human resource management. Voluntas: International Journal of Voluntary and Nonprofit Organizations 23(3): 605-635.

Roehl MT (2019) The impact of SHRM on the psychological contract of employees. Personnel Review 48(6): 1580-1595.

Roumpi D, Magrizos S and Nicolopoulou K (2019) Virtuous circle: Human capital and human resource management in social enterprises. Human Resource Management. DOI: $10.1002 / \mathrm{hrm} .22002$

Santos F, Pache A-C and Birkholz C (2015) Making hybrids work: Aligning business models and organizational design for social enterprises. California Management Review 57(3): 36-58.

Skelcher C and Smith SR (2015) Theorizing hybridity: Institutional logics, complex organizations, and actor identities: The case of nonprofits. Public Administration 93(2): 433-448.

Smith WK and Besharov ML (2019) Bowing before dual gods: How structured flexibility sustains organizational hybridity. Administrative Science Quarterly 64(1): 1-44.

Smith WK, Besharov ML, Wessels AK, et al. (2012) A paradoxical leadership model for social entrepreneurs: Challenges, leadership skills, and pedagogical tools for managing social and commercial demands. Academy of Management Learning and Education 11(3): 463-478.

Smith WK, Gonin M and Besharov ML (2013) Managing social-business tensions: A review and research agenda for social enterprise. Business Ethics Quarterly 23(3): 407-442.

Smith WK and Lewis MW (2011) Toward a theory of paradox: A dynamic equilibrium model of organizing. Academy of Management Review 36(2): 381-403. 
Teece DJ (2007) Explicating dynamic capabilities: The nature and micro foundations of (sustainable) enterprise performance. Strategic Management Journal 28(13): 1319-1350.

Teece DJ, Pisano G and Shuen A (1997) Dynamic capabilities and strategic management. Strategic Management Journal 18(7): 509-533.

Tracey P, Phillips N and Jarvis O (2011) Bridging institutional entrepreneurship and the creation of new organizational forms: A multilevel model. Organization Science 22(1): 60-80.

Tranfield D, Denyer D and Smart P (2003) Towards a methodology for developing evidenceinformed management knowledge by means of systematic review. British Journal of Management 14(3): 207-222.

Ulrich D (1997) Human Resource Champions: The Next Agenda for Adding Value and Delivering Results. Cambridge, MA: Harvard Business School Press.

Ulrich D, Brockbank W, Younger J, et al. (2012) Global HR Competencies: Mastering Competitive Value From the Outside in. New York, NY: McGraw Hill.

Ulrich D and Dulebohn JH (2015) Are we there yet? What's next for HR? Human Resource Management Review 25(2): 188-204.

Ulrich D, Younger J, Brockbank W, et al. (2013) The state of the HR profession. Human Resource Management Journal 52(3): 457-471.

Van den Broek J, Boselie P and Paauwe J (2014) Multiple institutional logics in health care: 'Productive Ward: Releasing Time to Care'. Public Management Review 16(1): 1-20.

Winkler A-L and Portocarrero F (2018) People management in social enterprises: B corporations. In: Brewster C and Cerdin J-L (eds) HRM in Mission Driven Organizations: Managing People in the Not for Profit Sector. Cham: Springer International Publishing; Imprint; Palgrave Macmillan, pp.221-235.

Wright PM and McMahan GC (1992) Theoretical perspectives for strategic human resource management. Journal of Management 18(2): 295-320.

Wright PM, Nyberg AJ and Ployhart RE (2018) A research revolution in SHRM: New challenges and new research directions. In: Buckley RP, Halbesleben JRB and Wheeler AR (eds) Research in Personnel and Human Resources Management. Bingley: Emerald Publishing, pp.141-161.

Zhang L, Zhang Y, Dallas M, et al. (2018) How perceived empowerment HR practices influence work engagement in social enterprises - A moderated mediation model. The International Journal of Human Resource Management 29(20): 2971-2999. 